\title{
3. Antígona en la Fenomenología del espíritu*. Consideraciones hegelianas sobre lo privado y lo público
}

Más que ninguna otra de las tragedias griegas existentes..., la Antígona de Sófocles dramatiza la urdimbre de lo íntimo y lo público, de la existencia privada y de la existencia histórica.

George Steiner

Se me ha pedido elaborar unas reflexiones sobre la forma en que la relación entre lo privado y lo público fue elaborada por Hegel en su sistema, y voy a centrar mi atención en la interpretación que él nos ofrece de la tragedia Antígona de Sófocles, en la que considera que se hallan representados los elementos que llevaron al mundo griego a su desintegración; mundo que, para gran parte de los contemporáneos de Hegel, se mostraba como un ideal de integración precisamente entre lo privado y lo público.

* Una primera versión de este artículo fue publicada en: Abello, Ignacio (comp.) (2005). Hacer visible lo visible: Lo privado y lo público. Bogotá: Departamento de Filosofía, Universidad de los Andes, 3-31. 


\section{¿Por qué la Fenomenología?}

Para conocer lo que piensa Hegel en último término acerca de las relaciones tensas que se dan entre lo privado y lo público, habría que acudir a la Enciclopedia de la ciencias filosóficas en su tercera parte, titulada "Filosofía del espíritu", y, en esta, a la sección dedicada al espíritu objetivo. La expresión en último término quiere decir que en la Enciclopedia encontramos la expresión última y más decantada de su pensamiento, ya que allí la exposición se desarrolla de manera estrictamente especulativa, es decir, sigue la pura dinámica de los conceptos, de modo que los asuntos son tratados en ella de acuerdo con su más estricta articulación lógica. Esto significa que los temas se desarrollan allí de acuerdo con la lógica de los puros conceptos, que corresponde a la articulación misma de la realidad; pero no significa que Hegel sustente con ello un dogmatismo prekantiano, donde el pensamiento parece reflejar como un espejo la realidad, sino que se trata de un idealismo en el que la articulación racional del devenir de lo real viene salir a la luz solo gracias a la conciencia que lo comprende.

Esta es, al menos, la pretensión del "idealismo absoluto" sustentado por Hegel. Pero entonces cabe preguntar: ¿para qué acudir a la Fenomenología del espiritu? ¿Qué interés puede tener lo que en esa obra dice Hegel acerca de la relación entre lo público y lo privado, si no se trata de su última palabra?

Como lo explica muy bien André Léonard, en su artículo "La estructura del sistema hegeliano", los grandes temas filosóficos reciben en el sistema una triple consideración, a saber, la objetiva, la subjetiva y la absoluta o especulativa. En la primera, la objetiva, el tema es tratado como proceso real o espacio-temporal, es decir, como acontecimiento de carácter histórico. Esta visión la encontramos expuesta en los llamados Cursos de Berlín, conformados por los apuntes de Hegel y los de sus alumnos en los cursos dictados por él en la Universidad de Berlín en los años finales de su carrera académica. En estos cursos, él desarrolla los que cabría llamar los cuatro temas fundamentales de su sistema, a saber, la historia, el arte, la religión y la filosofía, y lo hace desde la perspectiva histórica, tal como puede verse en 
sus Lecciones sobre la filosofía de la historia, la estética, la filosofía de la religión y la historia de la filosofia.

Ahora bien, en lo que atañe al tema de nuestro interés, es decir, a las rela- ciones entre lo privado y lo público, las reflexiones de carácter objetivo se hallan, sobre todo, cuando Hegel estudia el paso que se llevó a cabo entre el mundo cultural de la Grecia clásica y el mundo del Imperio romano, o sea, en el cambio de una organización social donde los intereses particulares y los intereses públicos se identificaban en la figura del ciudadano de la polis, a una sociedad imperial donde el individuo, en su abstracta singularidad de ciudadano, se ve alejado y confrontado a la abstracta universalidad del Estado; en otras palabras, donde lo privado y lo público llegan a su máximo desgarramiento.

Esta visión objetiva constituye el punto de partida para la cabal comprensión de un problema filosófico, y ello explica el hecho de que Hegel, en la Universidad de Berlín, en los últimos años de su carrera docente, haya ofrecido a sus alumnos esas visiones objetivas como el camino más adecuado para ingresar a su sistema filosófico. Sin embargo, esta visión debe conducir a una ulterior reflexión en la que el mismo tema aparezca interiorizado como momento de la conciencia en su configuración a través de la historia cultural de Occidente. En otras palabras, una realidad de envergadura filosófica no es solo un acontecimiento espaciotemporal, sino que tiene un significado para los seres humanos, no solo como individuos, sino como colectividad social.

Se trata, entonces, de la visión subjetiva que expone la Fenomenología del espíritu, en la cual los grandes temas filosóficos se van organizando como otras tantas "experiencias de la conciencia", siguiendo una articulación conceptual, claro está, pero condicionada esta vez por el carácter reflexivo de la conciencia. De ahí que la necesidad que articula esas experiencias de la conciencia se halle determinada por la estructura de esa misma conciencia, es decir, por la distinción entre sujeto y objeto, así como por su mutua e indisoluble relación marcada por el esfuerzo de la conciencia para superar esa distinción en pos de alcanzar la verdad. 
La Fenomenología expone, así, la forma en que el proceso de la cultura de Occidente ha ido dejando sus huellas en los diversos "estratos" de la conciencia tanto singular (conciencia, autoconciencia, razón) como colectiva (espíritu, religión, saber absoluto). Como bien lo señala el mismo Hegel, dado que la misma conciencia es la que, al autoconstituirse mediante su acto reflexivo, establece la distinción entre el sujeto y el objeto del conocimiento, es decir, entre ella y la realidad que le es ajena, será ella misma la que podrá examinar esa distinción sin tener que salir fuera de ella. A medida que la conciencia avanza en su autocomprensión, avanza igualmente en la comprensión del mundo, al ir corrigiendo progresivamente las diferencias que halla entre su concepción de la realidad y la manera como esta se le hace presente.

Es en este contexto y bajo esta perspectiva como examinaré aquí la tragedia de Antígona, como paradigma, para Hegel, de las tensiones que configuraban el mundo ético de la Grecia clásica y que lo llevarán a su desintegración para dar paso al Imperio romano. Pero se trata, como veremos, de un ejemplo paradigmático de las tensiones que experimenta toda conciencia en el seno de una sociedad que busca regirse por los criterios que establece la razón

Cabe señalar aquí lo que, en su estudio sobre el mito de Antígona, nos dice George Steiner al referirse precisamente a la interpretación que ofrece Hegel de esa figura trágica en la Fenomenología del espíritu:

Todo el discurso de Hegel representa una negativa a prestarle un carácter fijo, una definición formal. Esta negativa es esencial a su método y hace engañosos los conceptos de "sistema" y de "totalidad" que habitualmente se le atribuyen al hegelianismo. En Hegel, la reflexión y la expresión se mueven constantemente en tres niveles: el metafísico, el lógico y el psicológico, el último de los cuales abarca a los otros dos, en la medida en que trata de hacer explícitos los procesos de conciencia que generan y estructuran operaciones metafísicas y lógicas (Steiner, 2000, pp. 35-36). 
Aunque la cita refiere con buenas razones su apreciación a todo el discurso hegeliano, lo que dice específicamente con respecto a la preeminencia de lo psicológico sobre lo lógico y lo metafísico vale en particular para el texto de la Fenomenología, según lo señalado anteriormente sobre el carácter peculiar de esta obra y el papel que desempeña dentro del sistema global como exposición desde la perspectiva subjetiva, es decir, como "ciencia de las experiencias de la conciencia". Pero debemos entender, claro está, que el término psicológico tiene aquí el sentido muy amplio y muy general de subjetivo.

Finalmente, la consideración especulativa, es decir, estrictamente conceptual, tal como aparece en la Enciclopedia de las ciencias filosóficas (y en sus desarrollos parciales: la Ciencia de la lógica y las Lineas fundamentales de la filosofía del derecho), viene a coronar la exposición filosófica, al conciliar el carácter objetivo y el carácter subjetivo de las otras dos exposiciones, que aparecen, entonces, como momentos de la realización misma de la Idea. En otras palabras, si un tema como el de la configuración de la sociedad (lo privado y lo público) es visto en los Cursos como un acontecimiento histórico y en la Fenomenología como una experiencia de la conciencia, en la Enciclopedia se muestra como la realización del concepto mismo de sociedad mediante esa objetivación histórica y esa subjetivación experiencial, concepto que tiene su lugar, dentro del sistema, en el seno del espíritu objetivo, que corresponde a la filosofía del derecho.

Con ello debe quedar claro el sentido y los límites del examen que voy a realizar aquí sobre las relaciones entre lo privado y lo público en la Fenomenología del espíritu. Por una parte, la consideración fenomenológica del tema no solo tiene la ventaja de hacérnoslo ver como una experiencia humana fundamental en la configuración de la cultura occidental cristiana, sino que resulta ser indispensable para comprender el verdadero significado de un fenómeno de tal envergadura. Pero, por la otra, señala que esa lectura no puede considerarse como definitiva, y que, si pretendemos comprender toda la complejidad del fenómeno tal como la comprende Hegel, tendríamos no solo que atender a lo que nos dicen los Cursos de Berlín al respecto, sino también y sobre todo avanzar hasta la visión estrictamente especulativa de la Enciclopedia, y el 
indispensable complemento que nos ofrecen las Líneas fundamentales de la filosofia del derecho, en donde Hegel desarrolla por extenso la argumentación que sustenta las tesis presentadas en los esquemas enciclopédicos.

He dicho esto para señalar que mi exposición conlleva una doble limitación. Por una parte, supone en cierta forma la comprensión objetiva del conflicto entre lo privado y lo público, tal como la ofrece Hegel al analizar el paso de la polis griega el Imperio romano en su interpretación objetiva de la historia. Aunque algunos rasgos de este paso aparecerán reflejados en la exposición subjetiva de la Fenomenología, cabe señalar que la consecuencia objetiva de mayor trascendencia en este proceso histórico de la configuración de un Estado universal abstracto (Roma) vino a ser la elaboración del derecho romano, tal como fue desarrollado por los juristas latinos; porque, al perderse la seguridad que les ofrecía la polis griega a sus ciudadanos y romperse así la unidad entre los intereses privados y los públicos, vino a surgir un concepto abstracto y general de ciudadano, cuyas relaciones con un Estado igualmente abstracto y general debieron ser mediadas por una estructura jurídica de carácter universal, y por unas reglas claras de procedimiento para el manejo de los conflictos.

Por otra parte, la segunda limitación de mi exposición es que, para una cabal comprensión del problema que analizamos, sería necesario avanzar hasta el capítulo sobre el "Espíritu objetivo" de la Enciclopedia, complementado con su exposición detallada en las Líneas fundamentales de la filosofia del derecho, ya que es precisamente en esos textos, como lo he indicado antes, donde Hegel desarrolla una deducción puramente conceptual, es decir, estrictamente filosófica o especulativa, de las relaciones entre el concepto de Familia, como guardiana de los intereses singulares de sus miembros, de la sociedad civil, que salvaguarda los intereses particulares de las diversas asociaciones de ciudadanos, y de Estado, que integra ambos momentos en la universalidad de una organización racional.

Como lo subraya el mismo Hegel al finalizar la Enciclopedia (§ 574-577), cuando expone el concepto mismo de filosofía, la tríada de lo singular, 
lo particular y lo universal viene a configurarse en tres silogismos, de modo que en cada uno de ellos uno de esos tres elementos juega el papel de término medio. Con ello pretende elaborar un esquema formal que le permita, por de- cirlo así, agotar las diversas maneras como pueden entenderse las relaciones entre los intereses personales, los particulares y los universales en el seno de una sociedad moderna. Sin embargo, más allá de estas consideraciones muy generales, no voy a desarrollar aquí estos conceptos, ya que ello me sacaría de la consideración estrictamente "fenomenológica" que me he propuesto de- sarrollar. Solo he querido mencionarlos para determinar el sentido propio, aunque parcial, que tiene una reflexión sobre las relaciones entre lo público y lo privado a la luz de la Fenomenología del espíritu; porque solo si tenemos en cuenta esa parcialidad podemos hacerle justicia a la exposición hegeliana y aprovechar toda su riqueza, sin pretender esperar de ella lo que no puede ofrecernos.

Consciente, entonces, del sentido y de las limitaciones de mi exposición, quiero resaltar el doble el interés que tiene examinar la exposición de la tragedia de Antígona o de las relaciones entre lo público y lo privado desde la Fenomenología. Por una parte, porque esta visión subjetiva posee la gran ventaja de ofrecernos una exposición muy viva, digamos que existencial, de la raíz misma de todo conflicto social, así como de los caminos para solucionarlo, porque sitúa esa raíz en la estructura misma de la conciencia humana, tal como esta ha sido configurada por la larga experiencia de la historia cultural de Occidente. Por otra parte, porque nos ofrece elementos indispensables para entender uno de los temas que más controversia han suscitado en la interpretación de la filosofía hegeliana, a saber, su visión del Estado.

Tendremos ocasión de ver cómo el examen del conflicto que se establece, no propiamente entre lo privado y lo público, sino, de manera más compleja y fecunda, entre los intereses del individuo, los de la sociedad y los del Estado, es llevado a cabo por Hegel buscando salvaguardar uno de los más preciados logros de la civilización, como es el carácter intangible de la libertad del individuo. La superación de Kant, el filósofo que mejor comprendió el carácter a la vez singular y universal del individuo humano, y el que mejor supo 
propender a su salvaguarda, no puede hacerse, a los ojos de Hegel, sacrificando sus innegables logros, sino buscando situarlos dentro de una visión que los reintegre al seno de la sociedad de la cual provienen y a la cual se orientan.

Una justificación ulterior para examinar con especial atención la lectura que nos ofrece Hegel en la Fenomenología nos la da él mismo, en una consideración que hace con respecto a cada una de las figuras o experiencias de la conciencia, pero que entiendo puede aplicarse también a los diversos momentos de su sistema. Nos dice que hay que detenerse en cada uno de ellos como si fuera el único, buscando agotar su significado, porque en cada uno de ellos se expresa la totalidad de una manera particular y, por lo tanto, solo en la medida en que lo comprendamos nos será dado comprender también la necesidad de superarlo a fin de examinar esa misma totalidad desde una perspectiva ulterior.

Voy a pasar, entonces, a considerar el conflicto que se presenta entre los intereses privados y los públicos en una sociedad regida por principios racionales, tal como la expone el texto de la Fenomenología bajo la figura paradigmática de Antígona en la tragedia escrita por Sófocles. No voy, por supuesto, a examinar si la interpretación hegeliana del drama griego corresponde o no al espíritu de la obra misma, sino el uso que de él hace Hegel para presentar la tensión dialéctica que existe entre lo singular y lo universal en los orígenes mismos de la sociedad occidental. Cabe notar, sin embargo, que George Steiner ha considerado la interpretación que ha hecho Hegel de la tragedia de Sófocles como "delicada exégesis... profundamente original" (Steiner, 52).

\section{Ubicación de los textos}

Hegel habla de Antígona en la Fenomenología de manera expresa solo en dos ocasiones muy significativas. La primera es al terminar sus análisis sobre la individualidad, cuando se apresta a iniciar el examen del espíritu $(P h$. 236). Para comprender mejor esta ubicación, recordemos lo que nos dice Jean Hyppolite a propósito de esta obra de Hegel en su conjunto: 
La Fenomenología se propone una doble tarea: por una parte, conducir a la conciencia ingenua al saber filosófico y, por otra, hacer salir a la conciencia singular de su pretendido aislamiento, de su ser-para-sí exclusivo, para elevarla al Espíritu (1946, p. 311).

Para cumplir esta segunda tarea, el texto despliega, como ya lo he señalado, dos grandes escenarios, uno que corresponde a las experiencias de la conciencia individual (conciencia, autoconciencia, razón) y otro que corresponde a las experiencias de la conciencia colectiva (espíritu, religión, saber absoluto), con el propósito de mostrar cómo la primera conciencia hunde sus raíces en la segunda. Se podría resumir una de las tesis fundamentales de la Fenomenología diciendo que, para la conciencia, la verdad no consiste propiamente en la adecuación de un sujeto a un objeto, o de este a aquel, sino en la tarea de convertir un mundo dado en una producción de la razón, en una creación del espíritu.

Ahora bien, la primera referencia explícita a la tragedia de Sófocles la encontramos justo en el momento en que Hegel concluye la presentación del primer escenario (la conciencia individual) y se dispone a dar el paso al segundo (la conciencia colectiva). Esto quiere decir que la tensión entre lo individual y lo colectivo se ubica en el momento mismo de tomar conciencia de la existencia de lo colectivo como fundamento de lo individual, de modo que ese conflicto constituye su impulso básico. A su vez, el conflicto mismo se irá transformando a medida que la sociedad vaya adquiriendo formas más complejas de organización. No se trata, por lo tanto, de un conflicto particular o circunstancial, sino radical y fundacional.

Para ubicar el segundo texto en el que Hegel hace referencia a Antígona, conviene tener en cuenta que el segundo escenario, el de la conciencia colectiva, comienza con un examen de la llamada eticidad o espíritu verdadero, es decir, de la organización social básica constituida por ciudadanos libres, tal como Hegel la ve encarnada de manera ejemplar en el mundo griego y en su paso al mundo romano. Este examen se lleva a cabo en tres momentos. 
En el primero se expone la configuración de ese "mundo ético"; en el segundo se analiza "la acción ética" como expresión del conflicto que lo constituye, lo dinamiza e igualmente lo destruye; y en el tercero se muestra cómo la desintegración de ese mundo ético trae consigo la configuración de un Estado de derecho. Precisamente, cuando Hegel analiza el segundo momento, el de la "acción ética", aparece la segunda cita de Antígona que viene a servir de paradigma para visualizar la profunda contradicción que se halla en la raíz de ese mundo en apariencia ideal ${ }^{1}$.

Sin embargo, las alusiones a Antígona no se reducen a esos dos textos en los que se la menciona expresamente, sino que se hallan dispersas a lo largo de la exposición de esta primera parte del espíritu, es decir, de la configuración originaria de la conciencia colectiva o social de Occidente. La tragedia de Sófocles viene a ser, a los ojos de Hegel, la imagen viva de la fuerza y de las contradicciones de esa sociedad, que son a su vez la fuerza y las contradicciones que se hallan en las raíces de toda sociedad moderna. "Toda su interpretación de la ciudad griega - dice Valls Plana - es una interpretación de la tragedia de Antígona" (238). De ahí que el texto siga muy de cerca la estructura de la obra de Sófocles, al estar convencido de que el poeta ha sabido comprender mejor que nadie la urdimbre de su propia sociedad y las fuerzas que, a la vez que la mantienen viva y la impulsan, terminarán igualmente por destruirla. Ahora bien, para comprender mejor esto, conviene precisar un poco más la situación del texto dentro del proceso fenomenológico.

Para ello, tengamos en cuenta que el principio dinámico que impulsa la organización social lo sitúa Hegel en la "lucha por el reconocimiento". Sin entrar a detallar este principio dinámico, cuya estructura ha sido examinada con harta frecuencia desde muy diversas perspectivas, voy a fijarme en los que considero sus aspectos fundamentales. El ser humano, que se sabe distinto de su

1 Cabe recordar aquí el libro de Jacques Taminiaux: La nostalgia de Grecia en el amanecer del idealismo alemán.

2 Consideraciones muy significativas sobre el tema pueden leerse en Acosta (2010). 
animalidad inmediata, busca objetivar esa convicción mostrándose superior a la vida, pero esa objetivación de su certeza solo puede tener sentido para otra conciencia que se halle en iguales condiciones, es decir, solo puede lograrse mediante el reconocimiento por parte de un igual. No le basta, entonces, con poner en riesgo su propia vida para mostrar que está por encima de ella, sino que necesita contar para ello con el reconocimiento de sus semejantes. Los seres humanos no luchan solo para asegurar su sobrevivencia, como pensaba Hobbes, pero tampoco son naturalmente sociables, como pensaba Locke, sino que luchan a muerte entre sí, pero no solo para asegurar el sustento, sino sobre todo para lograr que se los reconozca como tales, es decir, como no siendo meros animales. En esta forma explica Hegel la "insociable sociabilidad" de los seres humanos, de la que hablara Kant, que se necesitan unos a otros, pero pareciera que se necesitaran precisamente para guerrear entre sí. Lo que sucede es que solo en y mediante esa lucha por el reconocimiento logran certificar y certificarse de su condición humana, elevada, gracias a la conciencia, por encima del estado de simple animalidad. La conciencia es así a la vez principio de superioridad y fuente de un profundo conflicto, lo que, en términos de Hegel, podría caracterizarse como un verdadero "destino" (Schicksal).

Sabemos también cómo entiende Hegel la superación de ese "estado natural" de conflicto, tan semejante y a la vez tan diferente del "estado natural" hobbesiano: la servidumbre y el trabajo son el camino hacia la liberación frente a la naturaleza al someterla y ponerla al servicio del hombre, con lo cual se supera también el miedo a la muerte que constituye la cadena por la cual el siervo se halla atado a su amo. Se lleva así a cabo una doble liberación de la autoconciencia: frente a la naturaleza y frente a los poderes humanos que la subyugan. Ahora bien, si dejamos a un lado una serie de consideraciones que, a pesar de su interés, nos apartarían de nuestro propósito, podemos ver que el concepto que orienta el avance de la conciencia singular hacía los fundamentos que la hacen posible es la objetivación de la razón en el mundo. En otras palabras, objetivar la razón en el mundo significa configurar un mundo de relaciones entre seres humanos que se reconozcan como tales, a saber, como sujetos libres capaces de asumir sus propios destinos. En la búsqueda de sus 
fundamentos conceptuales, tal como lo hace la conciencia en la Fenomenología, ella descubre que su propósito es configurar un mundo en el cual logre su anhelado reconocimiento, mundo que vendría a ser así la objetivación de la razón.

Tomemos en su realidad — dice Hegel— esa meta que es el concepto, el cual ya nos ha salido al paso, a saber, la autoconciencia reconocida que en la otra autoconciencia libre tiene su certeza de sí misma y en ella precisamente su verdad (Ph. 194).

En otras palabras, tratemos de entender hacia dónde avanza la conciencia en su proceso de conocerse a sí misma, y esa meta será precisamente el concepto que orienta sus pasos; concepto que, como dice Hegel, es "la autoconciencia reconocida que en la otra autoconciencia libre tiene así su propia certeza, y precisamente en ella su verdad". Y, para que lo comprendamos de manera adecuada, nos aclara luego que si hacemos que salga a la luz (herausheben) el espíritu interior presente allí, veremos aparecer "en este concepto el reino de la eticidad" (Ph. 194); reino que, como sabemos, configura una sociedad de individuos libres.

La búsqueda de reconocimiento, nos está diciendo Hegel, es el motor y la meta que impulsa a los seres humanos a organizarse en sociedad, y por ello las configuraciones sociales se hallan todas marcadas por ese elemento conflictivo que debe ser superado una y otra vez. Se trata de un conflicto que mantiene viva la estructura social, a la vez que amenaza constantemente con destruirla.

Si recordamos ahora que estas reflexiones se llevan a cabo dentro de la Fenomenología, es decir, como parte del proceso que sigue la conciencia moderna al examinar de manera sistemática las estructuras que la han hecho posible, lo que se nos quiere hacer entender es cómo el ser humano, en cuanto autoconsciente, necesita de una sociedad como ámbito para que su condición de individuo libre pueda ser realidad. "Porque — continúa Hegel— esta [la eticidad] no es otra cosa que la unidad espiritual absoluta de la esencia de los individuos en la realidad autosuficiente de los mismos" ( $P h .194)$. 
Tratemos de desentrañar un poco esta formulación que suena un tanto sibilina. Nos dice que el reino de la eticidad, es decir, la sociedad en cuanto tal, es una unidad espiritual, lo cual no puede extrañarnos, y que es además absoluta, es decir, existe como entidad autónoma e independiente. Esa unidad está conformada por la esencia de los individuos, lo que tampoco puede resultar extraño habiendo escuchado lo dicho antes: pertenece a la esencia de los individuos el organizarse en sociedad. Ahora bien, es en esa sociedad donde los individuos alcanzan su autosuficiencia efectiva o su efectividad autosuficiente; en otras palabras, es en ella y por ella que llegan a ser en realidad lo que son: seres libres.

Hegel no ve inconveniente en considerar que la configuración social no solo pertenece a la esencia misma de los seres humanos, sino que constituye la objetivación de la razón, la existencia de esta en el espacio y en el tiempo:

La razón es como la sustancia fluida universal, como la simple cosidad $^{3}$ inmutable, que de igual manera se dispersa en muchas entidades por completo autosuficientes, así como la luz en las estrellas como puntos innumerables que brillan por sí mismos (Ph. 194).

Por lo tanto, únicamente en la sociedad y por la sociedad los individuos pueden alcanzar la autosuficiencia que los caracteriza, y la razón es la que les otorga consistencia como individuos. El pensamiento de Hegel, en contraste con el de Hobbes o el de Kant, no considera que los individuos sean entidades últimas, autónomas, que además necesitan de los otros y de la sociedad, sino que en realidad no pueden ser tales individuos sino en y mediante su organización social: frente a una antropología que cabría llamar nominalista, tenemos aquí una claramente racionalista o idealista. El yo no puede concebirse sino desde un nosotros o, dicho en otros términos, la sociedad no es el

3 Hegel llama cosidad (Dingheit) a aquello que hace que una cosa, en su sentido más abstracto, sea una cosa; así, la razón es aquello que le otorga a la sociedad el carácter de cosa, de algo que está ahí y permanece. 
resultado de la unión de individuos autónomos que la constituyen mediante un pacto de convivencia, sino la condición de posibilidad de esos mismos individuos en cuanto autónomos.

Voy a dar de nuevo un salto, dejando de lado consideraciones sin duda del mayor interés, pero en las cuales no podemos detenernos, para concentrar la atención en nuestro objetivo: comprender la concepción que tiene Hegel de la sociedad o del "reino de la eticidad", a fin de penetrar en el significado que tiene para él la figura de Antígona como imagen que nos permite ver a la vez la esencia de la sociedad griega y el germen de su desintegración; desintegración que, como sabemos, no significa su simple desaparición, sino su "superación" (Aufhebung), es decir, su desaparición para convertirse en elemento a la vez negado y presente, o presente en cuanto negado, de la historia cultural que lo ha de suceder. Las tensiones que caracterizan a la sociedad griega, y que están en la base de toda organización social verdadera, es decir, de toda organización social que busque regirse por criterios racionales, se hallan a la vez negadas y presentes, o presentes en cuanto negadas, en todas las organizaciones posteriores que han venido surgiendo a partir de ella.

Ahora bien, para comprender ese "reino de la eticidad" es importante tener en cuenta que su concepto se hace claro para la conciencia como resultado de las contradicciones a las que conduce una reflexión ética como la kantiana, que se apoya de manera unilateral en la razón pura, en la razón del individuo que reflexiona sobre sí misma. Tenemos así un aspecto a la vez desconcertante y del mayor interés para entender la manera como procede la reflexión en el seno de la Fenomenología. Es claro que no se trata de una reflexión de carácter histórico, como ya lo hemos señalado, sino de una reflexión de la conciencia sobre su propia configuración; pero esta configuración es el resultado de una historia cultural que ha ido depositando en ella sus diversos estratos de significación. Por eso no debe resultarnos extraño que las figuras 
históricas hagan su aparición acá y allá, aunque no sigan un orden estrictamente cronológico ${ }^{4}$.

El resultado de una ética como la kantiana es un individualismo llevado hasta sus últimas consecuencias, en el que la razón, en su autonomía, pretende poder deducir las normas de su comportamiento a partir de sí misma, y en ese ejercicio de autoengendramiento se llega hasta el extremo de su propia negación: el individuo que reflexiona como individuo termina negándose en la universalidad de un sujeto moral anónimo como el kantiano. La idea básica de la crítica al individualismo, inherente a la ética de la pura razón, es que dicha razón viene a convertirse a la vez en legisladora y en crítica de su misma legislación, en una suerte de juez y parte en la configuración de las normas para su comportamiento. De ahí el carácter formal y, por lo mismo, vacío de esa doctrina ética: porque la razón tiene que legislar, pero tal como sucede con toda legislación que pretenda determinar la acción humana, tiene que ser concreta, es decir, referida a un aquí y un ahora; de modo que, al pretender hacerlo, cualquier ley particular va a caer bajo la crítica inmisericorde de esa misma razón abstractamente universal. En otras palabras, entre el carácter universal de la razón que legisla y el carácter singular del ser humano que actúa no aparece ninguna mediación que permita establecer un verdadero silogismo, como diría Hegel.

Y es precisamente ahí donde Hegel sitúa la raíz de las contradicciones que se producen entre lo singular y lo universal, entre lo privado y lo público. Será necesario, por lo tanto, establecer tal mediación, ya que sin ella la reflexión racional termina por negarse a sí misma y el Estado liberal termina por desintegrarse. Entre el individuo singular y el Estado universal deberá aparecer, en el mundo moderno, la sociedad civil como mediadora. Sin embargo, antes de llegar a ello, la historia deberá cumplir algunas etapas previas.

4 Sobre esto pueden verse: El tiempo y las experiencias de la conciencia y La estructura de la Fenomenología del espiritu (Díaz 1986, pp. 31-93). 
Es bueno detenernos un momento a examinar esta idea silogística de la lógica hegeliana, y me refiero aquí a su lógica en general, es decir, a su manera de pensar y de articular el discurso, y no propiamente a sus doctrinas lógicas en particular; aunque es claro que en ellas debemos encontrar en su momento la fundamentación de estas reflexiones. Me refiero a que la estructura de la realidad, pensada como un proceso de procesos y no como una red de realidades estáticas que además tendrían la propiedad de entrar en movimiento, tiene que ser pensada siguiendo la estructura lógica de lo que es un proceso en general. En otras palabras, una realidad "heracliteana" debe pensarse como un proceso puro, como un total devenir en el que aquello que parece ser "cosa" o "sustancia" no viene a ser más que un momento más o menos pasajero o consistente, pero un simple momento. Ahora bien, piensa Hegel: un proceso tiene siempre un punto de partida, un punto de llegada y un término medio, es decir, tiene la estructura formal de un silogismo en el que dos términos extremos son a la vez identificados y distinguidos por el término medio. Esta es la razón de pensar la realidad toda como un silogismo de silogismos 5 .

Ahora bien, comprender la sociedad como el fundamento de realidad para los individuos libres significa retornar en el tiempo a la cultura griega como primera manifestación, para Hegel, de un verdadero "reino de la eticidad", de una sociedad de individuos libres. Para mostrar la articulación conceptual de ese retorno, Hegel señala, al final del complejo capítulo dedicado a la razón, que esta se configura a la vez como legisladora y como juez de esa misma legislación (razón legisladora y razón que examina las leyes, es decir, Kant). Ahora bien, dice Hegel:

La esencia espiritual [la sociedad] es sustancia real [realidad concreta] porque esas [dos] maneras [es decir, la razón que legisla y la que examina las leyes] no valen cada una por sí, sino solo como superadas [como meros momentos], y la unidad, en

5 Ver los parágrafos finales de la Enciclopedia ( 5 574-577), donde Hegel resume mediante tres silogismos, en forma puramente conceptual (especulativa), lo que significa la filosofía como conocimiento de la totalidad en cuanto tal. 
la que ellas son solo momentos, es el sí-mismo de la conciencia que, a partir de aquí, es puesto en la entidad espiritual y la hace efectiva, plena y autoconsciente ( $P h .235)$.

Para entender estas últimas palabras debemos tener en cuenta que nos hallamos en el paso de la conciencia individual a la conciencia colectiva o intersubjetiva; porque, con la moral kantiana, la conciencia individual ha llegado a su pleno desarrollo conceptual hasta el punto de haber agotado su sentido y haberse convertido en una conciencia universal. El individuo moral kantiano tiene que obrar como un universal: "Obra únicamente según aquella máxima que tú puedas a la vez querer que se convierta en una ley universal" (Fundamentación, BA 52), reza el imperativo categórico. Con ello, el desarrollo fenomenológico da un gran salto, al pasar de lo singular a lo colectivo, de la razón al espíritu, por lo cual el análisis deberá recomenzar su recorrido en un nivel superior. Se trata del "sí-mismo de la conciencia que, a partir de aquí, es puesto en la entidad espiritual [la sociedad o la eticidad] y la hace efectiva, plena y autoconsciente".

Hegel pasa, entonces, a considerar las figuras de la conciencia colectiva, es decir, de la sociedad, que para él tienen su primera figura paradigmática en la Grecia clásica, como ya tuvimos ocasión de señalarlo. Las sociedades anteriores en la historia se caracterizaban porque en ellas solo era libre uno o unos pocos, mientras que todos los demás eran siervos.

En el seno de una sociedad como la griega, que busca guiarse por los dictados de la razón, viene a darse un comienzo real de reconocimiento, de modo que en ella el acto de legislar y el examen de las leyes vienen a ser momentos de su unidad orgánica, ya que allí la conciencia ha entrado a forma parte como tal, es decir, como autónoma, de esa entidad espiritual, es decir, de la sociedad. Lo que caracteriza a una tal sociedad es que en ella los individuos están presentes no solo, o no principalmente, como meros singulares, sino como universales, como ciudadanos dotados de razón e iguales en pleno derecho. 
Esta relación inmediata de los universales con la sociedad como lo universal trae como consecuencia que la sociedad misma sea percibida como "una ley eterna, que no tiene su fundamento en la voluntad de este individuo, sino que es en y para sí6 la pura voluntad de todos absoluta que tiene la forma del ser inmediato" (Ph. 235). En otras palabras, la sociedad no es percibida como una creación humana, sino como una realidad autónoma, válida por sí misma, atemporal, que expresa, sí, la voluntad de todos, pero tiene la forma de algo dado de antemano. Hegel tiene cuidado en señalar que una ley así no implica para la autoconciencia una obediencia "a un señor cuyos mandatos fueran un capricho, y en los cuales ella no se reconociera", sino que sus leyes "son pensamientos de su propia conciencia absoluta que ella misma tiene de manera inmediata" (Ph. 235). Al subrayar la palabra tiene, Hegel hace notar que la autoconciencia sabe que participa de la conciencia colectiva absoluta que ha elaborado esa ley eterna, pero que ella misma no es tal conciencia. Y al señalar que los tiene de manera inmediata, está indicando que poseen un carácter natural o simplemente dado, que deberá ser superado. Por otra parte, la relación de cada conciencia con esa ley no es propiamente una fe, "porque la fe - dice Hegel - también ve ciertamente la entidad [en la que cree], pero como algo ajeno", mientras que "la autoconciencia ética, por la universalidad de su sí-mismo, es una de manera inmediata con la entidad [a la que obedece]" (Ph. 235 ). En otros términos, por su calidad de ciudadano libre no percibe la norma de conducta colectiva cono algo ajeno que se le impone desde fuera, sino como parte de su propia naturaleza, de su propia esencia.

Recordemos las palabras de Antígona, donde aparece la frase que cita Hegel a este propósito, y que constituyen el clímax de la confrontación con Creonte. Ella sabe que va a ser condenada por haber quebrantado la prohibición de enterrar a su hermano, pero sabe igualmente que tenía que cumplir ese deber aunque le costara la vida:

6 La expresión alemana "en y para sí" (an und für sich) corresponde en español a "por sí misma", solo que Hegel suele jugar con el sentido de esos términos, y por ello conviene traducirla al pie de la letra. 
No fue Zeus el que los ha mandado publicar [los decretos a los que ella obedece y por cuya obediencia se ha visto acusada], ni la Justicia que vive con los dioses de abajo la que fijó tales leyes para los humanos. No pensaba que tus proclamas tuvieran tanto poder como para que un mortal pudiera transgredir las leyes no escritas e inquebrantables de los dioses. Estas no son de hoy, ni de ayer, sino de siempre, y nadie sabe de dónde han surgido. No iba yo a obtener castigo por ellas de parte de los dioses por miedo a la intención de hombre alguno (Antígona, 450-459; el resaltado es propio).

El hilo conductor que guía la reflexión de Hegel, en este paso fundamental de la Fenomenología, es que un examen a fondo de la estructura de la conciencia moderna viene a culminar en la ética kantiana y en sus inevitables contradicciones, por tratarse precisamente de la más acabada comprensión del individuo en cuanto realidad absoluta o válida por sí misma. Ahora bien, cuando un concepto agota su significación, permite ver con claridad sus propios límites y la necesidad de superarlos. La contradicción fundamental de esa ética se encuentra en la separación original que establece entre las dos funciones de una razón puramente formal que pretende ser legisladora universal, pero que, en virtud de su propia lógica, se ve reducida a no ser más que examinadora de leyes que le son dadas y en cuyo origen ella no ha tomado parte. Y la superación de esa contradicción viene a darse cuando ambos momentos, el legislativo y el crítico, logran reconciliarse en la unidad superior de una sociedad desde la cual la conciencia existe en realidad como tal. Una verdadera ética, nos está diciendo Hegel, no puede construirse a partir de una pura razón abstracta, sino que tiene que elaborarse en diálogo con las normas y costumbres de una verdadera sociedad conformada por ciudadanos con iguales derechos. Que el legislar y el examinar las leyes se hayan mostrado como nulos, significa que ambos, tomados de manera singular y aislada, son solo momentos inconsistentes de la conciencia ética; y el movimiento en el que se presentan tiene el sentido formal de que es la sustancia ética — la sociedad - la que se manifiesta a través de ellos. 
La sociedad integra, entonces, los dos momentos, el legislador y el crítico, es decir, aquel por el cual la razón legisla y aquel por el cual juzga la leyes que ella misma elabora, y el movimiento en el que ambos se hacen presentes como momentos hace ver que una tal sociedad es una entidad consciente, es decir, que no obedece a un proceso ciego, sino que sus configuraciones responden a una lógica.

Si mi comprensión del texto es la correcta, lo que Hegel nos está haciendo ver es que, dentro de una entidad espiritual de ciudadanos libres, aun en el caso tan precario e inicial como lo fue la Grecia clásica, las normas de conducta deben ser consideradas en principio como normas racionales, en el sentido de que cuentan con lo que podríamos llamar una "presunción de racionalidad", es decir, deben considerarse como racionales mientras no hayamos demostrado lo contrario; y, además, que solo en esa sociedad resulta posible ejercer la verdadera libertad. En ello consiste precisamente la articulación lógica que conecta los dos grandes escenarios de la Fenomenología, el de la conciencia singular y el de la conciencia colectiva: únicamente sobre el trasfondo de una verdadera sociedad resulta posible comprender el significado último de la conciencia humana, así como su estructura tanto cognoscitiva como volitiva.

Considero conveniente insistir en que, en el paso que se lleva a cabo entre el final de la razón, es decir, la figura de la individualidad, y el comienzo del espíritu, es decir, la eticidad, puede verse claramente cómo la Fenomenología no avanza siguiendo un recorrido histórico, aunque las figuras históricas estén siempre presentes como figuraciones de las experiencias que examina la conciencia. Por eso no debe extrañarnos que al finalizar el desarrollo de la "individualidad", donde se examina la doctrina moral kantiana, se pase a considerar, en el espíritu, la articulación de la sociedad griega; porque Hegel ha venido examinando las experiencias de la conciencia individual, cuya manifestación más elevada la ofrece esa moral kantiana, y va a pasar entonces a considerar los fundamentos de esa conciencia individual que se hallan precisamente en la configuración de la sociedad cuyos orígenes encuentra en Grecia. 


\section{Las dos leyes}

Para analizar la estructura de esa entidad ética que fue la sociedad griega y descubrir el sentido de la contradicción que se halla en su misma naturaleza, Hegel comienza señalando que "el Espíritu en su verdad simple es conciencia y desdobla sus momentos" (Ph. 240), lo que para un lector de la Fenomenología resulta casi un lugar común: ser conciencia o ser consciente es precisamente establecer la distinción entre la misma conciencia y su objeto, de modo que esa distinción no debe pensarse como una condición del acto de ser consciente, sino más bien como su resultado. Sobre esta verdad fundamental gira en buena medida la reflexión fenomenológica, o lo que cabría llamar la doctrina hegeliana del conocimiento. Heredada sin duda de Fichte, la tesis dice que el acto de conocer no consiste en la relación que se establece entre un sujeto preexistente al acto y un objeto igualmente preexistente, sino que, en el acto mismo por el cual la conciencia se constituye como tal, es ella la que "pone" el objeto como su otro; en otros términos, la distinción sujeto-objeto no es previa a la conciencia, ni la condiciona, sino que es su mismo resultado.

Ramón Valls Plana nos lo explica muy claramente:

Hegel nos da la razón de toda división en el seno del espíritu. El espíritu se desdobla porque "es conciencia y desdobla sus momentos". Conciencia significa siempre oposición de subjetividad o certeza y objetividad o verdad. El espíritu es conciencia y tiene que devenir perfectamente autoconsciente (219).

Lo que va a poner en marcha ese desdoblamiento es la acción (Handlung), que se halla en el centro de la atención desde el comienzo del análisis del mundo ético, pero que a su vez merecerá una consideración particular en el segundo momento (La acción ética...), el cual desempeña el papel de término medio que conecta el mundo ético con el Estado de derecho, es decir, la polis griega con el mundo del Imperio romano. 
El texto con el cual se inicia la consideración sobre la "eticidad" o "espíritu verdadero" es muy denso, y vale la pena analizarlo brevemente, porque presenta en forma muy condensada la dialéctica que va a desarrollarse a continuación. Voy a transcribirlo y luego trataré de explicarlo:

La acción lo separa [al espíritu] en la sustancia y la conciencia de esa misma sustancia; y separa tanto a la sustancia como a la conciencia. La sustancia, como entidad y fin universal, se confronta a la realidad singularizada; el término medio infinito es la autoconciencia, la cual, siendo en sí unidad de sí misma y de la sustancia, se vuelve ahora para sí, reúne la entidad universal y su realidad singularizada, eleva esta última hasta aquella y obra éticamente, y hace descender aquella hasta esta y realiza el fin, [es decir,] la sustancia solo pensada; hace surgir la unidad de su sí-mismo y de la sustancia como su obra, y por ende como realidad (Ph. 240-241).

Aunque la formulación es muy abstracta, la idea general parece clara: la acción ética, es decir, aquella que se hace de acuerdo con la ley que constituye a la sociedad, confronta al ciudadano con la sociedad (conciencia de la sustancia y sustancia), de la misma manera como, gracias al acto de tomar conciencia, nos vemos confrontados al mundo como aquello que se yergue ante nosotros. Ahora bien, ese desdoblamiento no se lleva a cabo únicamente entre el ciudadano y la sociedad, sino igualmente en el uno y en la otra; en la sociedad, porque esta se muestra a la vez como realidad y como meta que debe alcanzarse, y en el ciudadano, porque este se ve a sí mismo como entidad en sí, es decir, como mero elemento de esa sociedad (sustancia) y como ser autoconsciente y activo en ella (para sí).

Ahora bien, en la confrontación de la sociedad con el individuo, el término medio que los une y los separa es la autoconciencia misma que, siendo, como hemos visto, simple unidad de sí misma y de la sociedad (ciudadano), toma distancia frente a la sociedad mediante su reflexión y actúa éticamente, al unificar la entidad universal o el fin con lo singular mediante un 
doble movimiento: elevando la singularidad a lo universal, ya que no obra en su propio beneficio sino en el de la sociedad, y haciendo descender la universalidad abstracta o la idea de sociedad a la singularidad de su acción. Con ello, la sociedad, entidad puramente ideal o pensada, se realiza como fin, de modo que esa unidad de la conciencia con la sociedad viene a ser obra de la conciencia que de esa manera realiza la sociedad.

Voy a dejar de lado algunas consideraciones que presenta Hegel mediante las cuales busca conectar lo que está sucediendo ahora en el seno de la conciencia colectiva con lo que había sucedido antes, en el primer escenario, es decir, en la conciencia individual; y voy a fijar la atención en la manera como se configura esa división entre el ciudadano y la polis bajo la figura de las dos leyes, la humana y la divina.

El texto comienza por señalar cómo la comunidad o la esencia o entidad común (Gemeinwesen), al ser realidad ética consciente, es para el ciudadano (autoconciencia en general) su verdadera sustancia, "el espíritu absoluto realizado en la multiplicidad de las conciencias que están-ahí" (Ph. 242). Esta formulación no puede dejar de llamar la atención, ya que, en la terminología hegeliana, viene a decirnos que la sociedad es para los ciudadanos la realización de la entidad suprema (espíritu absoluto), especie de encarnación divina que, "en cuanto sustancia real es un pueblo y en cuanto conciencia real es ciudadano del pueblo" (Ph. 242). Sin embargo, no voy a detenerme a examinar estas formulaciones que tienen el aire de una religiosidad sin trascendencia, a la manera de Spinoza

Hegel señala cómo, al tratarse de una realidad espiritual, el mundo ético lleva en su seno una división fundamental entre universalidad y singularidad, entre sentido último y realidad concreta; división que se encarna en dos formas diferentes de ley, la divina y la humana. Esta última se presenta como una realidad consciente de sí misma mediante sus normas claramente expresadas, tiene la forma de su universalidad en la "ley conocida y la costumbre presente" y se encarna de manera singular en el gobernante. Frente a ella y sirviéndole de fundamento se halla "la ley divina", que configura "la esencia 
inmediata y simple de la eticidad" (Ph. 242), y que, "en cuanto universalidad real, es una violencia contra el ser-para-sí individual", es decir, obliga a los singulares a obrar en contra de sus intereses particulares.

Conviene tener en cuenta, para evitar confusiones frecuentes en la interpretación de Hegel, que las realidades espirituales no se distinguen entre sí como cosas, una por completo diferente de la otra, sino en forma especulativa, es decir, de tal manera que cada una se refleja en la otra y la contiene (speculum = espejo). "Esto no debe extrañarnos — comenta Valls Plana—, porque ya nos ha avisado Hegel que todas la divisiones del espíritu no son adecuadas, sino que un extremo o polo abarca siempre al polo opuesto" (1994, p.221).

Ahora bien, si la singularidad en la cual se encarna la ley humana es el gobernante como legislador y guardián de las leyes, la singularidad en la que se encarna la ley divina es la familia como comunidad ética natural.

Oigamos la explicación que nos da Hegel acerca de la diferencia entre el ámbito de lo público y el ámbito de lo privado, diferencia que desembocará a la confrontación entre las leyes de la ciudad y las leyes ancestrales:

Por lo tanto, si la esencia o entidad común (Gemeinwesen) es la sustancia ética en cuanto obrar real consciente de sí, entonces el otro lado tiene la forma de la sustancia inmediata o entitativa. Esta última es así, por un lado, el concepto interno o la posibilidad universal de la eticidad como tal, pero tiene igualmente en ella, por el otro lado, el momento de la autoconciencia. Esta, al expresar la eticidad en ese elemento de la inmediatez o del ser, o al expresar una autoconciencia inmediata como esencia y también como ese sí-mismo en un otro, es decir, una esencia o entidad común ética inmediata, es la familia ( $P h .242)$.

Ensayemos una traducción de este lenguaje tan conceptual y abstracto a uno más cercano y concreto. Por una parte, dice el texto, tenemos que la sociedad como esencia o entidad común (Gemeinwesen) tiene un aspecto consciente 
y uno natural. En el primero se elaboran las leyes de la polis, mientras que el otro tiene a su vez dos caras, una abstracta, que Hegel llama "el concepto interno o la posibilidad universal de la eticidad como tal", es decir, la idea misma de sociedad, y otra cara concreta o autoconsciente que, al expresar la eticidad de manera inmediata o al expresar un modo de ser consciente a la vez singular y colectivo, viene a ser la familia. Para expresarlo en forma todavía más sencilla, podemos decir que la familia es la forma más simple e inmediata del ser social, o, para decirlo en lenguaje tradicional, la familia viene a ser la sociedad en potencia, o el "germen" de la sociedad.

Según esta forma de analizar la conformación de la sociedad, el conflicto al que conducen la dos leyes, la humana y la divina, la consciente y la inconsciente, la mediada y la inmediata, cuando se ponga en marcha la acción humana, será entre la familia y el gobierno, o, más en general, entre las costumbres ancestrales representadas por Antígona y las normas estatales representadas por Creonte.

En este conflicto hay dos aspectos que Hegel busca resaltar, siguiendo el texto de la tragedia, y para los cuales elabora una peculiar justificación. Se trata de que la familia venga a ser la guardiana del deber con los muertos, y de que la mujer, como hermana, sea la responsable por el cumplimiento de ese mismo deber. En el primer caso, la argumentación señala que la familia, como entidad ética, no está conformada por las relaciones meramente naturales entre sus miembros, "porque lo ético es en sí universal", y aunque la relación entre sus miembros es "de Naturaleza, es esencialmente también un espíritu, y solo como entidad espiritual es ética. Habrá [entonces] que ver en qué consiste su peculiar eticidad" (Ph. 243).

Como lo ético es lo universal en sí o en principio, la relación ética entre los miembros de la familia no es el mero sentimiento o el amor; y si bien es cierto que esa eticidad descansa sobre las relaciones de los miembros singulares con el todo familiar, y que "el fin peculiar y positivo de la familia es el singular como tal", no puede tratarse de la acción de los miembros "según su contingencia, como ocurre, por caso, en alguna ayuda o servicio. El contenido de 
la acción ética tiene que ser sustancial o entero y universal; por lo tanto solo puede referirse al singular como un todo o como universal" (Ph. 243).

Veamos, entonces, cómo explica Hegel que esa relación ética familiar, que esa acción de la familia sobre sus miembros, tenga como destinatario a quien ha fallecido:

Por lo tanto, la acción que abarca la existencia entera del consanguíneo y lo tiene a él [...] como su objeto y contenido, a este singular perteneciente a la familia como una entidad universal exonerada de la realidad sensible, es decir, singular, no concierne ya al viviente sino al muerto, quien, desde la larga serie de su estar-ahí disperso, se ha compendiado en la plena configuración única, y, desde la intranquilidad de la vida contingente, se ha elevado a la tranquilidad de la universalidad simple (Ph. 244).

Inspirado, sin duda, por la fuerza de la obra trágica de Sófocles, Hegel insiste una y otra vez en el sentido y la profundidad que tiene ese deber familiar de enterrar a los miembros difuntos, así sea de una manera simbólica, como en el caso de Antígona, que se redujo a arrojar algo de tierra sobre el cadáver de su hermano. Hegel está convencido de que el sentido de la tragedia apunta a elementos muy significativos y profundos en la constitución de la sociedad, y dejan ver las fuertes tensiones que la habitan. Tensiones, por lo demás, que forman parte imborrable de la experiencia colectiva de la cultura occidental. Un poeta con la fuerza de Sófocles tuvo que transmitir la experiencia profunda de su propia sociedad, de modo que sus recursos poéticos no pueden ser reducidos a simples creaciones de su fantasía, sino que dan a entender articulaciones profundas que no son accesibles a la simple vista.

La familia, como entidad ética o espiritual, debe luchar por erradicar todos los elementos naturales para sustituirlos con elementos de su propia creación, es decir, humanos. Se trata, como podemos ver, de manifestaciones concretas de esa lucha por el reconocimiento, de ese esfuerzo titánico de los seres 
humanos por superar su condición de simples vivientes, de simples animales; lucha que atraviesa todo el texto de la Fenomenología.

La muerte es un acontecimiento natural, y la desintegración del cadáver por los elementos biológicos lo es igualmente, de modo que la intervención de los familiares busca suplantar esos procesos naturales con acciones de significación espiritual. Oigamos una vez más a Hegel:

Esa universalidad a la que llega el singular como tal es el puro ser, la muerte; es el haber-llegado-a-ser inmediato y natural, no el obrar de una conciencia. Por eso la obligación del miembro familiar es añadir este aspecto, para que también su último ser, este ser universal, no pertenezca únicamente a la Naturaleza y se quede en algo irracional, sino que sea algo hecho y se afirme en él el derecho de la conciencia. O el sentido de la acción es más bien que, puesto que en verdad la tranquilidad y universalidad del ente autoconsciente no pertenecen a la Naturaleza, se elimine la apariencia de ese acto que la Naturaleza se ha arrogado y se restituya la verdad ( $P h .244)$.

Creo que estos pasajes son suficientemente claros para quien se detenga a considerarlos con atención. Revelan la profunda impresión que ha debido causar en Hegel la lectura de la tragedia de Sófocles, en la cual busca desentrañar el sentido profundo que mueve la acción de los participantes; porque la muerte se halla presente allí en un doble sentido: en la obligación que mueve a Antígona a rendirle ese último homenaje a su hermano muerto, obligación que ella asume, a su vez, a sabiendas de que su cumplimiento, al transgredir la orden dada de no enterrar a quienes hubieran muerto luchando contra la ciudad, le acarrearía su propia muerte. Por cumplir el deber con el muerto ella enfrenta su propia muerte.

Valls Plana ve en ello, creo que con buenas razones, un reflejo del espíritu cristiano que orienta la argumentación hegeliana: 
Una vez más podemos observar aquí la idea central, típicamente cristiana, que preside el desarrollo hegeliano. Combate una afirmación inmediata de lo singular. La verdadera singularidad subsiste solamente en lo universal, pero para insertar al individuo en la universalidad espiritual y real es necesario que el individuo se someta a la muerte. Una muerte, empero, que no es definitiva, sino que significa una resurrección, porque reintegra al singular al suelo de la universalidad real que lo sustenta (1994, p.224).

Sin embargo, considero que esa "resurrección", a la que alude Valls Plana, no debe entenderse en un sentido estrictamente cristiano, porque no parece haber indicios en la obra hegeliana de una verdadera fe en la "resurrección de la carne", tal como la anuncia la doctrina tradicional del cristianismo.

Ahora bien, en cuanto al segundo aspecto que Hegel se propone resaltar en el conflicto que marca la eticidad griega, a saber, que le corresponde a la mujer como hermana el cumplimiento de ese deber con los muertos de la familia, la argumentación se apoya igualmente sobre el carácter ético de la unidad familiar. Ese carácter ético le sirve para justificar la superioridad de la relación entre hermano y hermana (Polinices y Antígona) sobre las otras dos relaciones familiares: la de esposos y la de padres e hijos. En estas dos últimas, aunque también éticas y por lo tanto espirituales, se mezclan elementos naturales tales como el deseo, el amor o el vínculo biológico, los cuales determinan una desigualdad entre los términos relacionados y le otorgan a la relación un carácter pasajero, ya que su eje central son los hijos cuyo destino se halla por fuera de la relación familiar.

Sin entrar a examinar las detalladas consideraciones que hace Hegel a este respecto, y que darían pie a un interesante análisis de su concepción de los géneros, recojamos las conclusiones centrales en una larga cita:

La relación sin mezcla se da entre hermano y hermana. Ellos son la misma sangre, pero que en ellos ha llegado a su tranquilidad y equilibrio. Por eso no se desean, ni tampoco el uno le 
ha dado al otro ese ser-para-sí, ni lo ha recibido, sino que son mutuamente individualidades libres. Por lo tanto, lo femenino, como hermana, tiene el supremo presentimiento de la entidad ética; no llega hasta la conciencia y la realidad de la misma, porque la ley de la familia es la esencia que-es-en-sí, interior, que no se halla en la luz de la conciencia, sino que se queda en sentimiento interior y en lo divino despojado de realidad (Ph. 247).

No viene al caso examinar en detalle la forma en la que Hegel analiza el papel de la mujer en esta relación, y precisar si ese papel se halla condicionado por la estructura de la sociedad griega, o si es considerado por él como inherente a la naturaleza femenina. En todo caso, y acorde con la visión de muchos de sus contemporáneos sobre la Grecia antigua, se trata de un mundo con características idílicas, en el que reina un sereno equilibrio entre sus fuerzas contrapuestas:

El todo es un tranquilo equilibrio de todas las partes, y cada parte es un espíritu nativo que no busca su satisfacción más allá de sí, sino que la tiene dentro de sí, porque él mismo se halla en ese equilibrio con el todo (Ph. 249).

Sin embargo, Hegel se muestra ajeno a una visión romántica que pretendiera ver la sociedad griega como un paraíso perdido y que añorara ese pasado irrecuperable. Lejos de caer en la añoranza, la considera solo como una primera etapa que tenía que ser superada, y busca descubrir precisamente el origen de su desintegración que debía hallarse en el interior de su misma naturaleza, en su misma esencia. La superación hacia etapas superiores de organización social, aunque no por ello más felices, se lleva a cabo en virtud de las tensiones internas que tiene toda sociedad, y que, como nos lo había anunciado desde un comienzo, entrarán a ejecutar su labor demoledora en el momento en que sus dos polos contrapuestos se pongan en acción. 
Jean Hyppolite lo ha expresado de manera muy clara, a la vez que ha proyectado la desintegración que está por venir:

La ciudad antigua, donde el ciudadano se eleva de manera inmediata a la universalidad, y la familia antigua, donde el sí mismo singular es salvado de la muerte misma y conservado en su singularidad universal, forman una bella totalidad donde lo universal y lo singular todavía no se oponen. La sustancia es allí como pueblo una sustancia individual, no es todavía una sustancia abstracta —el destino- que se opone a los individuos. El sí mismo no es todavía allí singularidad negativa, exclusión de todo lo otro, sino que se halla presente solo como una sombra, como la sangre de la familia. Estos son los dos momentos que se van a desarrollar hasta la oposición; el destino en su noche vendrá a ser el que devore las individualidades del reino ético, y esas individualidades, al perder su carácter inmediato, llegarán a ser el sí mismo abstracto de las personas (1946, p. 336).

\section{La acción ética o la desintegración}

En el centro mismo de esa contradicción estará presente la autoconciencia individual que buscará ser reconocida por una sociedad en la que la negatividad que caracteriza a la individualidad no es tenida en cuenta. El texto nos los dice, al comenzar a examinar "la acción ética, el saber humano y divino, la culpa y el destino":

Pero tal como está constituida la oposición en este reino [de la eticidad], la autoconciencia no se ha presentado aún en su derecho como individualidad singular: ella vale en él, por una parte, solo como voluntad universal y, por la otra, como sangre de la familia; este singular vale únicamente como la sombra irreal (Ph. 251). 
El texto es claro y señala cómo, en esa eticidad inmediata, el individuo como tal no ha obtenido su verdadero reconocimiento. Para ello entrará en juego la acción como intervención del singular como tal, del individuo, según rezaba ya el antiguo adagio: actiones sunt suppositorum (las acciones corresponden a los sujetos). Ahora bien, como el individuo no obtiene en ese mundo ético el debido reconocimiento, su presencia no podrá ser sino perturbadora. Basta recordar la figura de Sócrates, el "tábano", tal como nos la dejó plasmada Platón.

Esa colisión se produce en la sociedad griega, dice Hegel, porque los elementos contrapuestos (las dos leyes), que se acreditan y se complementan mutuamente para establecer el equilibrio de la polis, entran en acción:

[El acto] perturba la tranquila organización y movimiento del mundo ético. Lo que en este último aparece como orden y concordancia de sus dos entidades, cada una de las cuales acredita y completa a la otra, se convierte, por el acto, en un paso de contrapuestos en el que cada uno demuestra ser más la anulación de sí mismo y del otro que su acreditación; se convierte en el movimiento negativo o en la necesidad eterna del horroroso destino que devora, en el abismo de su simplicidad, tanto la ley divina como la humana, así como también a ambas autoconciencias en las que estos poderes tienen su estar-ahí, y para nosotros pasa al ser-para-sí absoluto de la autoconciencia puramente singular (Ph. 251).

El proceso de desintegración social que Hegel atribuye, como he dicho, a la irrupción del individuo singular en el ambiente paradisiaco del mundo ético es experimentado por sus actores, o por quienes lo padecen, como una fuerza ajena y superior, como un "destino" que no logran comprender. Pero "para nosotros", es decir, para quienes con Hegel y gracias a él nos es dado comprender el sentido de lo que está sucediendo, se trata en realidad del paso necesario desde la tranquilidad de la eticidad inmediata a la afirmación unilateral y abstracta de la pura autoconciencia, es decir, a la afirmación del 
sujeto individual que, como en el caso del Imperio romano, se va a encontrar perdido y anónimo en su igualdad meramente jurídica frente a un Estado de derecho universal e igualmente abstracto.

Fiel a su principio fundamental según el cual todo proceso o movimiento busca superar una inmediatez de carácter natural para convertirla en una mediación de carácter racional o espiritual, y orientado por la búsqueda de reconocimiento, es decir, de negación de todo lo natural para sustituirlo por una acción humana — dos modalidades de una misma forma lógica—, Hegel señala una doble inmediatez que caracteriza al mundo ético y que será destruida por la irrupción de lo individual. Por una parte, la decisión inquebrantable con la que cada una de las dos conciencias involucradas sabe de su deber y lo cumple sin atender a las consecuencias, $\mathrm{y}$, por la otra, la distribución natural de las funciones entre los dos sexos: "Ahora bien, la conciencia ética sabe qué es lo que tiene que hacer; y está decidida a pertenecer ya sea a la ley divina o a la humana" $(P h .252)$. Porque, al no tener conciencia del carácter absoluto de su singularidad, como la tienen los hombres modernos, acepta como un destino el deber que su respectiva ley le impone y con el cual se identifica sin hesitación.

La contradicción entre una y otra se fundamenta, entonces, en la "decisión inmediata" que cada una asume para sí, descartando a la otra, y en el hecho de que esos "poderes éticos" se vuelven reales precisamente en autoconciencias concretas:

Ahora bien, dado que la eticidad, por un parte, consiste esencialmente en esta decisión inmediata y por lo tanto para la conciencia solo una de las leyes es la esencia, y que, por otro lado, los poderes éticos son reales en el sí-mismo de la conciencia, estos adquieren el significado de excluirse y contraponerse; en la autoconciencia ellos son para sí, mientras que en el reino de la eticidad son únicamente en sí (Ph. 252). 
Las palabras finales de esta cita son un ejemplo claro de la diferencia que establece Hegel entre ser-en-sí y ser-para-sí; en el primer caso se trata de una realidad que está ahí pero no es efectiva, es decir, que está en potencia, mientras que en el segundo caso esa misma realidad se hace efectiva, pasa, dirían los escolásticos, de la potencia al acto. Las tensiones que mantenían al mundo ético en equilibrio inestable, pero tranquilo, irrumpen con la acción humana y se convierten en fuerzas autodestructivas. Por eso, cuando esas dos leyes, encarnadas en sujetos individuales (Antígona y Creonte), se enfrenten, cada una ve en la otra la injusticia. Para la conciencia que cumple lo mandado por la ley divina, Antígona, la acción del gobernante se percibe como "violencia", mientras que para la conciencia que obedece a la ley humana, Creonte, la acción de enterrar al familiar muerto aparece como desobediencia y tozudez.

El conflicto adquiere así el carácter de una verdadera tragedia, porque ambos poderes contrapuestos tiene su propia razón, su propia justificación racional, pero resultan ser incompatibles. Una y otra son conciencias éticas que no obran por un interés personal:

Su absoluto derecho consiste en que, al obrar de acuerdo con la ley ética, no encuentran nada diferente en esa realización a no ser el cumplimiento mismo de esa ley, y el acto no muestra algo diferente de lo que es el actuar ético (Ph. 253).

Resuena aquí la dura fórmula kantiana para caracterizar una acción moralmente correcta: obrar el deber únicamente por el deber.

Ahora bien, para entender mejor la dialéctica que orienta el carácter destructor de la acción del individuo sobre el tranquilo mundo ético, conviene tener en cuenta dos aspectos que Hegel combina y que vienen a determinar en forma muy peculiar su comprensión de un tema particularmente complejo y significativo en el análisis de la cultura occidental cristiana, a saber, la culpa. Se trata de la lucha por el reconocimiento como hilo conductor de la acción humana, y de cómo ese reconocimiento se lleva a cabo mediante la superación o negación de la naturalidad, es decir, de lo simplemente dado 
No cabe duda de que el concepto de culpa, tal como aparece dentro de la cultura griega precristiana, presenta características que no parecen compaginarse con la comprensión cristiana del mismo. ¿Por qué Edipo se considera culpable de la muerte de su padre y de haber cohabitado con su propia madre, siendo que ambas acciones fueron ejecutadas por ignorancia? ¿Y por qué Antígona, al menos en la interpretación que hace Hegel, acepta ser culpable al enterrar a su hermano Polinice, cuando obra en obediencia al mandato de su propia ley? Sin embargo, lo que puede desconcertarnos aún más es lo que dice Hegel en el párrafo que presento a continuación:

La culpa no es la indiferente entidad ambivalente de que el acto, tal como se halla realmente a la luz del día, pueda ser un actuar de su sí-mismo o no, como si con el actuar pudiera conectarse algo exterior y contingente que no perteneciera al actuar, aspecto por el cual el actuar no sería entonces culpable. Sino que el actuar es él mismo ese desdoblamiento de ponerse a sí para sí y, frente a este, poner una ajena realidad externa; que tal realidad sea, pertenece al actuar mismo y es por medio del mismo. Por eso, inocente es únicamente el no-actuar como el ser de una piedra, ni siquiera el de un niño ( $P h .254)$.

El texto comienza rechazando la idea de que los actos humanos puedan ser o no ser conscientes, puedan ser actos que por algo ajeno a ellos, como sería la intención del sujeto que los hace, pudieran declararse inocentes. Todo acto humano, por el solo hecho de serlo, va acompañado del sí mismo, de la conciencia del sujeto que lo ejecuta. De ahí concluye Hegel, si entiendo bien el texto, que toda acción humana por el solo hecho de serlo implica una culpa, y es esto lo que él cree poder leer en las tragedias griegas, al menos en las dos a las que hace expresa referencia en los textos que comentamos: Antígona y Edipo Rey. Tanto Hyppolite como Valls Plana, y a su manera también A. Kojève, han tratado de entender esto al señalar una distinción entre el concepto de culpa que aparece aquí y el que vendrá a hacerse presente con el cristianismo. 
Es posible que esta manera de leer el texto pueda validarse en parte, pero yo quisiera más bien invertir los términos y ver en ello una reinterpretación del concepto cristiano de culpa a la luz de la conciencia griega, porque es esta última la que le sirve de hilo conductor a Hegel para el análisis de la acción ética, con lo cual busca combinar, como hemos visto, dos elementos: que el móvil más radical de las acciones humanas es la búsqueda de reconocimiento, y que ese reconocimiento se logra mediante la negación de todo lo natural, de todo lo simplemente dado. La acción humana, cuando es en verdad humana, es decir, ética, o sea, cuando es resultado de una reflexión sobre el deber, es una afirmación del sujeto que implica una ruptura con el orden natural y una irrupción en ese orden universal para someterlo a la singularidad del sujeto. Y es precisamente esa inevitable ruptura la que se halla en el origen del concepto de culpa; culpa, viene a decir Hegel, que adquiere entonces el significado de delito, "porque, como simple conciencia ética, se ha dirigido hacia una de las leyes, mientras que ha negado la otra y la ha infringido con su acto" $(P h$. 254).

No se trata, entonces, de un libre albedrío indiferente y ambivalente, como algo añadido a la acción y que podría disculparla. Eso, a los ojos de un convencido "spinocista" como Hegel, no puede darse. Es el obrar humano como tal el que se vuelve culpable, porque se trata de la afirmación absoluta y excluyente del individuo singular frente a la universalidad de la ley. ¿Quién no escucha aquí los ecos del rigorismo moral kantiano, que cubre con un manto de sospecha todas las acciones humanas por la posibilidad de que no hayan sido hechas por el puro respeto al deber por el deber, es decir, por lo puramente universal?

Lo que resulta realmente extraño y debe llamar nuestra atención es que, mientras que Spinoza concluía, a partir de la negación del libre albedrío, que no existe en realidad la culpa, que el arrepentimiento no es una virtud y que el hombre en realidad es inocente con aquella inocencia que parece caracterizar a una antropología "pagana", es decir, no cristiana; Hegel, en cambio, deduce la consecuencia contraria: el hombre, precisamente por no tener un libre albedrío en el sentido tradicional del término, es decir, por no poder obrar en 
contra de los dictados de su conciencia, es culpable, porque con ello transgrede el orden universal. Esto solo puedo comprenderlo desde la perspectiva de una racionalización del concepto cristiano de "pecado original": el ser humano, por su finitud, es un ser limitado cuya acción no puede menos de someter la universalidad de la ley que rige el orden del mundo a su limitada capacidad de acción. Es en este sentido que el ser humano es pecador por su misma naturaleza de ser finito.

Ahora bien, este esfuerzo de Hegel por reducir a términos racionales un concepto como el de pecado original, y buscar integrarlo con el racionalismo spinocista que niega el concepto mismo de pecado, resulta muy cuestionable, porque, para la teología cristiana, se trata de una doctrina revelada en el sentido estricto del término, es decir, no reducible a términos racionales, ya que solo puede conocerse porque Dios se ha dignado darla a conocer al ser humano. La doctrina del pecado original apunta a señalarle a los seres humanos que no pueden pretender cumplir con su deber moral sin la ayuda indispensable de Dios, sin la gracia, de modo que por sí mismos son incapaces de obrar bien. Es en este punto donde Lutero sitúa el meollo mismo del mensaje cristiano.

Ahora bien, si quitamos el elemento de revelación, la interpretación de Hegel se vuelve problemática, aunque podría tal vez leerse a la luz de la conclusión a la que parece llegar, por su parte, otro gran racionalista como es Leibniz, de que el pecado no puede ser más que el subproducto de una inevitable finitud de la criatura, el reconocimiento de que la acción humana no puede adecuarse por sí misma a los cánones de una ley universal, porque el sujeto que la ejecuta debería poder disponer de un conocimiento infinito que no está en sus manos alcanzar. Cuando obramos, tenemos que hacerlo en gran parte a ciegas, tratando de ser tan racionales como nos sea posible, sabiendo siempre que no estamos en condiciones de llegar a conocer si en realidad eso era lo que deberíamos haber hecho.

Entiendo que Hegel busca sintetizar a su manera la inocencia pagana, tal como la entendió Spinoza con su racionalismo consecuente, y la culpabilidad 
cristiana, que ha sido sin duda una de las fuentes principales del carácter absoluto que ha adquirido el ser humano como individuo. Porque alguien que es capaz por sí mismo de obrar sin ninguna limitación ajena, ni siquiera la de su propio entendimiento, es porque posee una voluntad infinita o ilimitada que, como lo dijera Descartes, nos hace semejantes a Dios. Pero esa síntesis o reconciliación dialéctica implica negar el concepto de pecado, tal como lo ha concebido la mayor parte de la tradición cristiana, para convertirlo en la conciencia de la finitud, y reinterpretar la necesidad de la gracia, para entenderla como la conciencia de esa misma insuperable finitud, con lo cual nos vemos remitidos, ya sea a una aceptación heroica de esta, como parece proponerlo Nietzsche con su ateísmo, o a reconocer que el sentido último de los seres humanos se halla más allá de ellos mismos, como parece proponerlo Hegel con su teísmo racionalista.

Esta manera extraña, y sin duda novedosa, de entender el obrar humano es la que lleva a Hegel a interpretar el clamor de Antígona como reconocimiento de una culpabilidad de la cual solo puede ser consciente a posteriori, una vez ejecutado el acto y en virtud del sufrimiento que el mismo acarrea: "Porque sufrimos, reconocemos que hemos cometido una falta"

7 En realidad, el texto de Sófocles permite diversas lecturas, algunas de las cuales no parecen adecuarse a la interpretación que ofrece Hegel. Debo esta aclaración a la oportuna indicación del colega Alfonso Correa. 
